\title{
Aerosol delivery through high flow nasal cannula compared to biphasic positive airway pressure, at two different pressure: an in-vitro study
}

Marina E. Boules ${ }^{1}$, Nabila Ibrahim Laz², Ahmed A. Elberry ${ }^{3}$, Raghda R. S. Hussein ${ }^{1}$ and Mohamed E. A. Abdelrahim ${ }^{1 *}$

\begin{abstract}
Background: Both non-invasive ventilation and high flow oxygen therapy are preferred over low flow oxygen therapy in many conditions. Nebulizers, for aerosol delivery, can be used within them without interrupting the circuit. The present study aimed to compare the efficiency of drug delivery within high flow nasal cannula (HFNC) and biphasic positive airway pressure (BiPAP) ventilation mode using two different inspiratory positive airway pressures. The aerosol delivery was examined in HFNC system at low flow, $5 \mathrm{~L} \mathrm{~min}^{-1}$, and BiPAP non-invasive ventilation under 2 different pressures [high pressure; inspiratory positive airway pressure/expiratory positive airway pressure (IPAP/EPAP) of $20 / 5 \mathrm{~cm}$ water, and low pressure; IPAP/EPAP of $10 / 5 \mathrm{~cm}$ water]. The total inhalable dose (TID) was measured by inserting an Aerogen Solo nebulizer installed with $1 \mathrm{~mL}$ salbutamol respiratory solution $\left(5000 \mu \mathrm{g} \mathrm{mL}^{-1}\right)$ within the circuit, and the salbutamol was collected on an inhalation filter placed in a filter holder connected to a breathing simulator. The breathing simulator was adjusted at a tidal volume of $500 \mathrm{~mL}$, respiratory rate of 15 breaths $\mathrm{min}^{-1}$, and inhalation to exhalation (I:E) ratio of 1:1 for the adult setting. In each technique of the three (HFNC, and low, and high-pressures BiPAP), TID was determined 5 times $(n=5)$. For particle size characterization, cooled Anderson Cascade Impactor (ACl) was inserted instead of the inhalation filter and the breathing simulator with the same scheme. In each technique of the three, particle size characterization was determined 3 times $(n=3)$.

Results: The BiPAP mode at low inspiratory pressure had the highest TID, followed by HFNC at flow $5 \mathrm{~L} \mathrm{~min}^{-1}$, then BiPAP mode at high inspiratory pressure. There was a significant difference only between low and high inspiratory pressure modes of BiPAP mode. Low-inspiratory pressure BiPAP delivered the highest mean \pm SD fine particle dose (FPD). It was significantly higher than that delivered in high inspiratory pressure BiPAP, and HFNC. Also, FPD in HFNC was significantly higher than that in high inspiratory pressure BiPAP. HFNC system had the smallest mass median aerodynamic diameter (MMAD) and the highest FPF followed by low then high inspiratory pressure BiPAP.
\end{abstract}

Conclusions: Increasing the inspiratory positive airway pressure in BiPAP, from 10 to $20 \mathrm{~cm}$ water, decreased the total inhalable dose and FPF nearly by half. Low inspiratory pressure BiPAP delivered the highest TID and FPD. The HFNC system at low oxygen flow resulted in the least MMAD, and the highest FPF. Using HFNC delivered a TID that was nonsignificant from that delivered by low inspiratory pressure BiPAP.

\footnotetext{
*Correspondence: mohamedemam9@yahoo.com

${ }^{1}$ Clinical Pharmacy Department, Faculty of Pharmacy, Beni-Suef

University, Beni-Suef, Egypt

Full list of author information is available at the end of the article
}

(c) The Author(s) 2021. Open Access This article is licensed under a Creative Commons Attribution 4.0 International License, which permits use, sharing, adaptation, distribution and reproduction in any medium or format, as long as you give appropriate credit to the original author(s) and the source, provide a link to the Creative Commons licence, and indicate if changes were made. The images or other third party material in this article are included in the article's Creative Commons licence, unless indicated otherwise in a credit line to the material. If material is not included in the article's Creative Commons licence and your intended use is not permitted by statutory regulation or exceeds the permitted use, you will need to obtain permission directly from the copyright holder. To view a copy of this licence, visit http://creativecommons.org/licenses/by/4.0/. 
Keywords: Oxygen therapy, Nasal cannula, Biphasic positive airway pressure, Inspiratory pressure Graphical Abstract
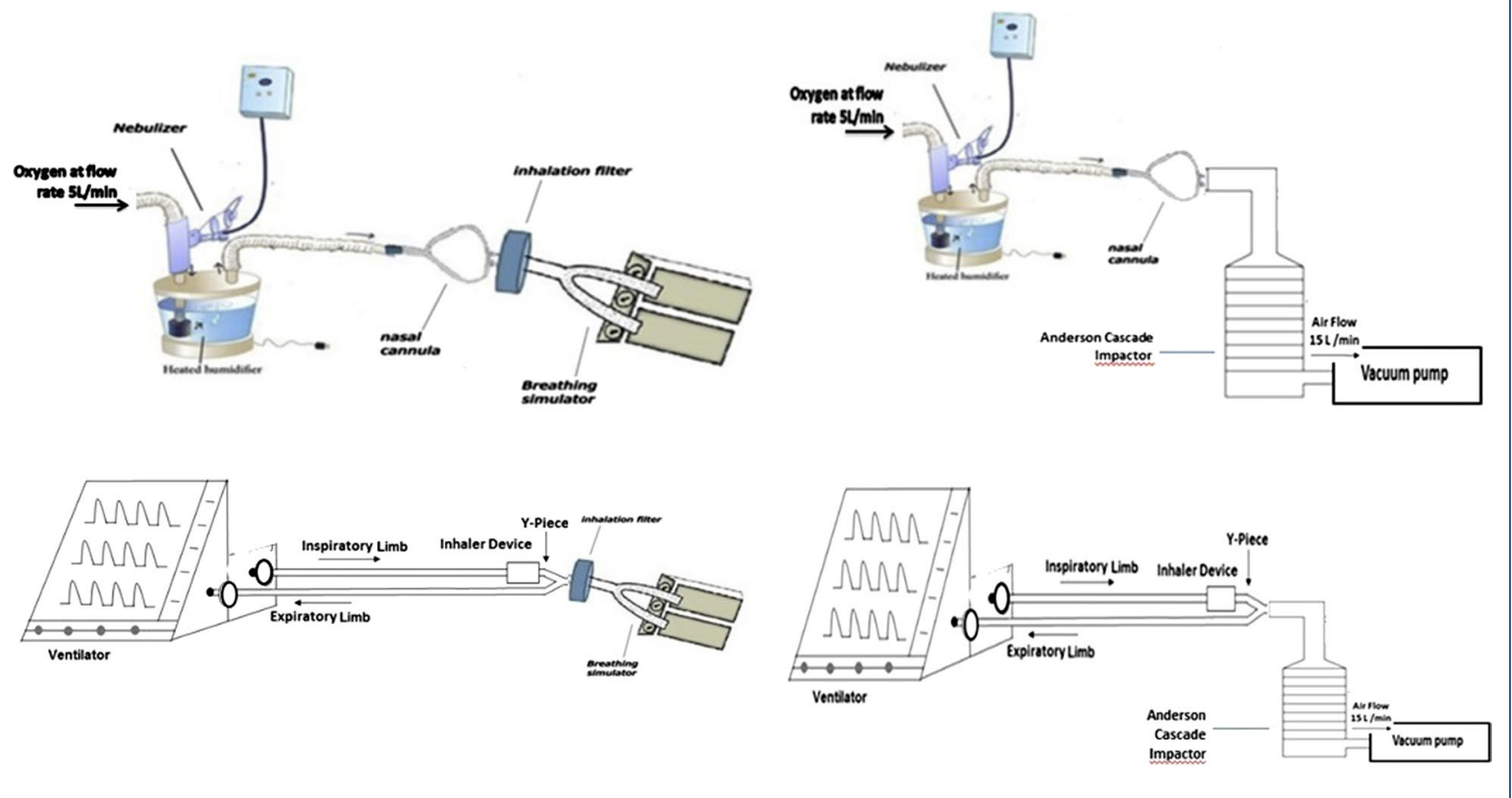

\section{Background}

Non-invasive ventilation (NIV) uses a close-fitting mask or a special nasal prong without the use of an endotracheal tube [1,2]. Available ventilation modes include [controlled mandatory ventilation (CMV), synchronized intermittent mandatory ventilation (SIMV), Assist control (AC), intermittent mandatory ventilation (IMV), biphasic positive airway pressure (BiPAP), continuous positive airway pressure (CPAP), jet ventilation, and high-frequency oscillatory ventilation (HFOV)]. The NIV helps to increase the survival rate in acute or chronic respiratory failure patients and relieve symptomatic sleep apnea [1,3]. Bronchodilators and other drugs may be needed by patients on NIV [4]. Nebulizers like a jet and vibrating mesh nebulizers can be used for the delivery of aerosols in patients during NIV $[5,6]$.

The BiPAP is composed of continuous flow at two levels of pressure, inspiratory positive airway pressures, which allows the tidal volume to be delivered, and expiratory positive airway pressure (EPAP). Its advantage is that it enables the patient to breathe spontaneously without the risk of high airway pressure. Consequently, patient-ventilator asynchrony and sedation requirements are decreased [1]. Besides, it helps in avoiding intubation, improving outcomes of patients with hypoxemia [7-9]; it also facilitating extubation [10]. On the other hand, its implementation is difficult, certain resources are required, and patient discomfort is common [11].

The high flow nasal cannula (HFNC) can be used as a drug delivery route to help in delivering medications without interrupting the normal routine, especially when oxygen is already needed through the cannula $[12,13]$. However, some barriers may face nebulization during HFNC. The aerosol may deposit in the high flow therapy circuit due to humidification, and high flow and in the nose and rhino-pharynx, due to the turbulent gas flow which reduces the delivery of the medication to the lungs. [13]

On the other hand, there is an increase in the use of HFNC system [14] to help in improving oxygenation and comfort for respiratory failure patients because it is easy to implement, tolerated as avoids nasal dryness caused generally by the oxygen therapy, and clinically effective [14-18]. Some studies suggested that high-flow nasal oxygen therapy is more effective to improve oxygenation with many physiological advantages than low flow oxygen therapy [11, 19-21]. Also, better respiratory rates, blood oxygen, and improved life scores were reported by delivery through HFNC than through masks [22].

The current study aimed to compare the efficiency of drug delivery using HFNC and BiPAP ventilation mode using two different inspiratory positive airway pressures as shown in Fig. 1. 


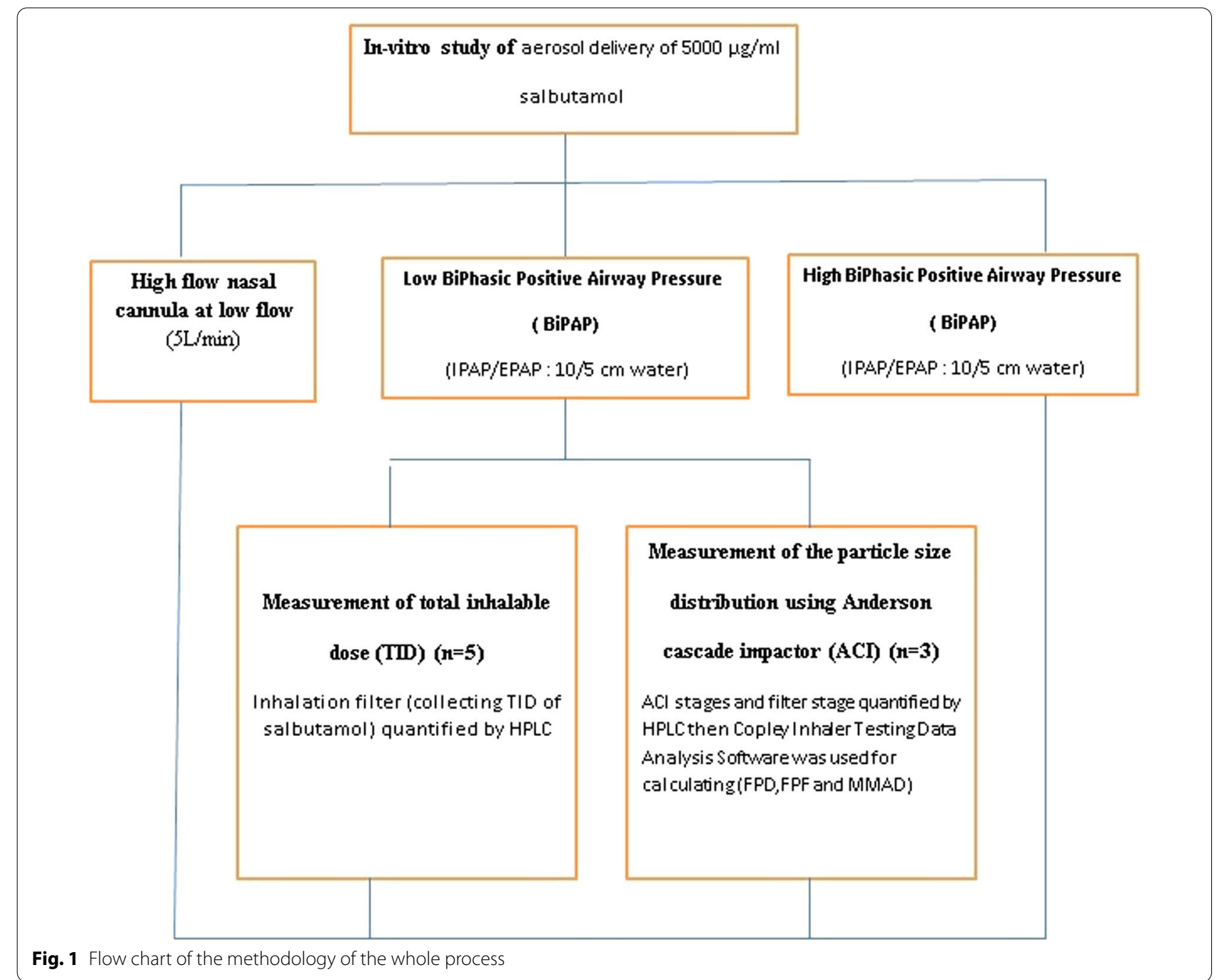

\section{Methods}

\subsection{Delivery systems}

One $\mathrm{mL}$ of salbutamol respiratory solution (Farcolin respirator solution, $5000 \mu \mathrm{g} \mathrm{mL}{ }^{-1}$; Pharco Pharmaceuticals, Cairo, Egypt), containing $5000 \mu \mathrm{g}$ salbutamol, was nebulized using the Aerogen Solo [SOLO] nebulizer (Aerogen Limited, Galway, Ireland).

\subsection{Measurement of total inhalable dose}

The total inhalable dose (TID) was delivered by three different techniques; adult nasal cannula in HFNC system at low oxygen flow, $5 \mathrm{~L} \mathrm{~min}^{-1}$, $[13,23]$ and NIV facemask using different pressures at BiPAP mode. Aerogen Solo vibrating mesh nebulizer (SOLO; Aerogen Limited, Ireland), was connected to the HFNC system upstream just before the humidifier (MR810 Fisher \& Paykel, Fisher\& Paykel Healthcare Limited, New Zealand) as shown in Fig. 2 [13, 19]. The humidifier was adjusted to deliver oxygen at $37{ }^{\circ} \mathrm{C}$ and $100 \%$ relative humidity. An electrostatic filter pad (inhalation filter) enclosed in a filter holder (Pari GmbH, Starnberg, Germany) was connected to the nasal cannula (Jiaxing Sim Medical Device Co., Limited, Zhejiang China) to collect the TID then was connected to a breathing simulator model (model 5600i, Michigan Instruments, Grand Rapids, USA).

SOLO was inserted in the ventilation circuit in the inspiratory limb of the BiPAP before the Y piece of the dual limb ventilation circuit as shown in Fig. 3 [24]. The $\mathrm{Y}$ piece was then connected to the inhalation filter in a filter holder that was connected to the breathing simulator. The bi-level ventilator (Bellavista 1000e, Imtmedical, Buchs, Switzerland) was adjusted at two different pressures; one with IPAP $20 \mathrm{~cm}$ water and EPAP $5 \mathrm{~cm}$ water and the other with IPAP $10 \mathrm{~cm}$ water and EPAP $5 \mathrm{~cm}$ water. 


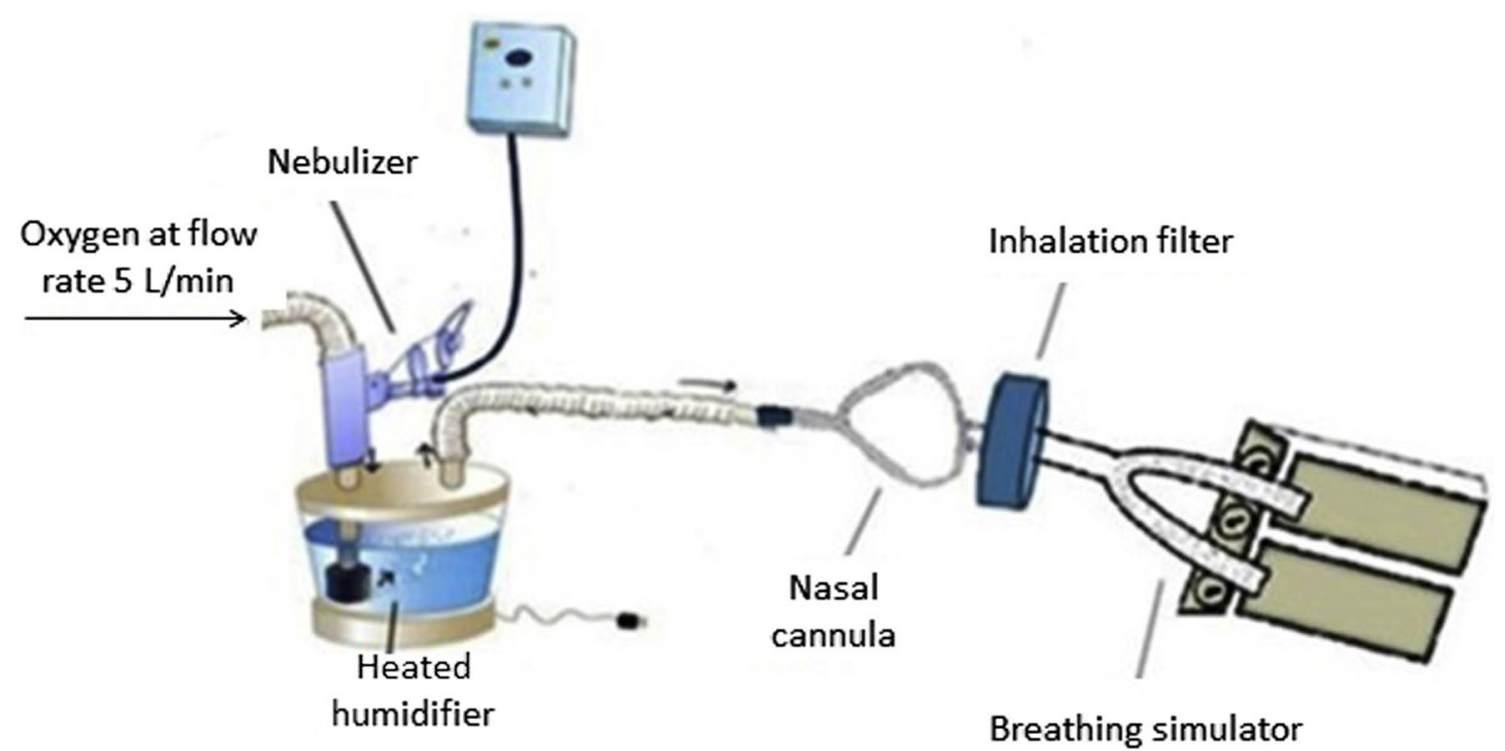

Fig. 2 Schematic diagram showing the measurement of the total inhalable dose using high flow nasal cannula system at oxygen flow $5 \mathrm{~L}$ min ${ }^{-1}$ [19]. SOLO vibrating mesh nebulizer was connected to the HFNC system upstream just before the humidifier which was connected to the nasal cannula. An electrostatic filter pad (inhalation filter) enclosed in a filter holder was then connected to the nasal cannula to collect the TID then was connected to a breathing simulator model

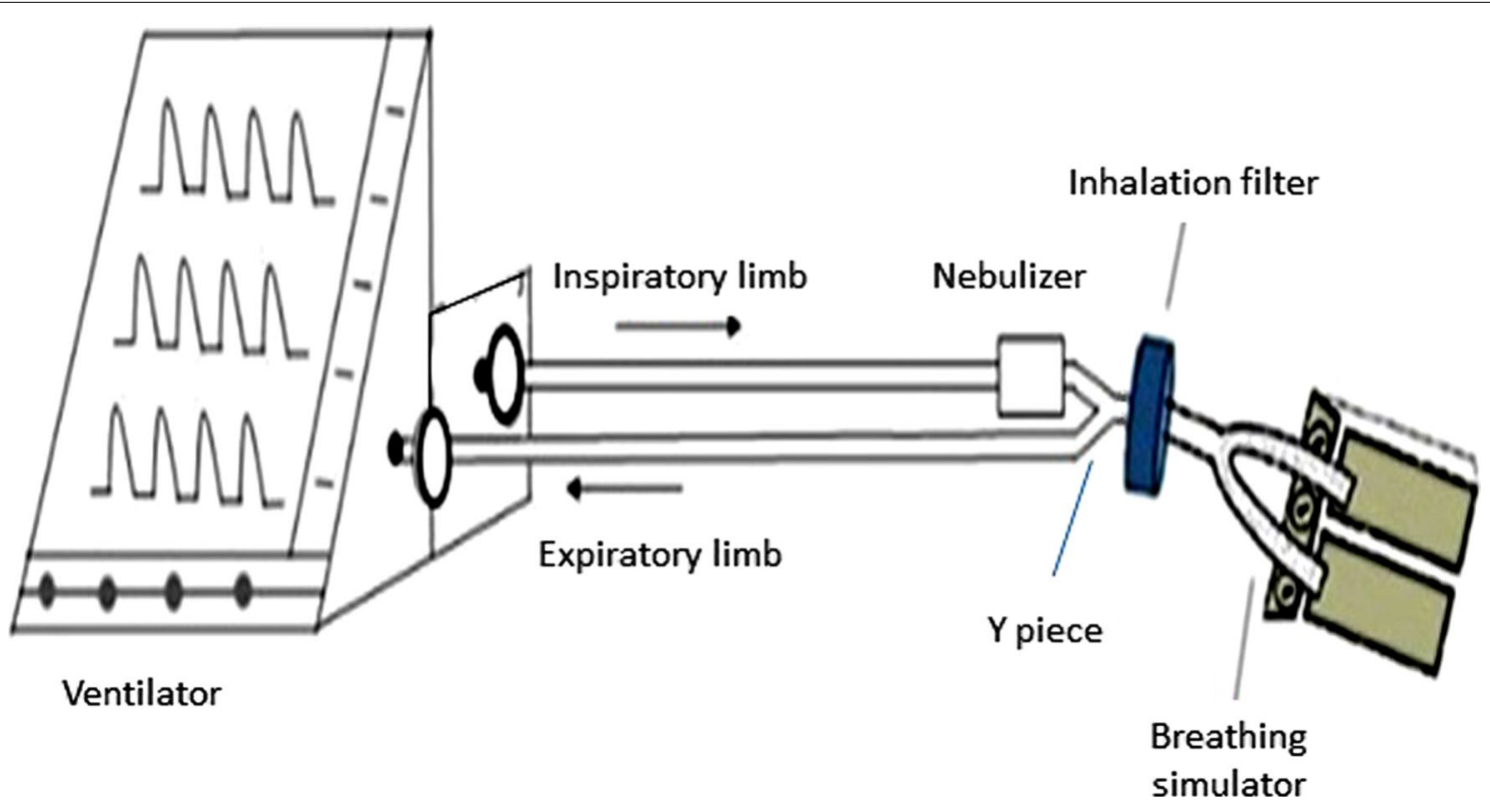

Fig. 3 Schematic diagram showing the measurement of the total inhalable dose using BiPAP mode, Modified from ElHansy et al. [24]. SOLO vibrating mesh nebulizer was inserted in the ventilation circuit in the inspiratory limb of the BiPAP (before the Y piece of the dual limb ventilation circuit). The inhalation filter, to collect the TID, was then connected to the Y piece then the breathing simulator was connected. The bi-level ventilator was adjusted at two different pressures; IPAP/EPAP 20/5 cm water and IPAP/EPAP 10/5 cm water

The breathing simulator in the three techniques was adjusted at a tidal volume of $500 \mathrm{~mL}$, respiratory rate of 15 breaths $\mathrm{min}^{-1}$, and inhalation to exhalation (I:E) ratio of $1: 1$ for the adult setting [25]. In each technique of the three, TID was determined 5 times $(\mathrm{n}=5)$ and SOLO continued to dry.

The amount entrained on the inhalation filter, SOLO reservoir, and each circuit tube was collected 


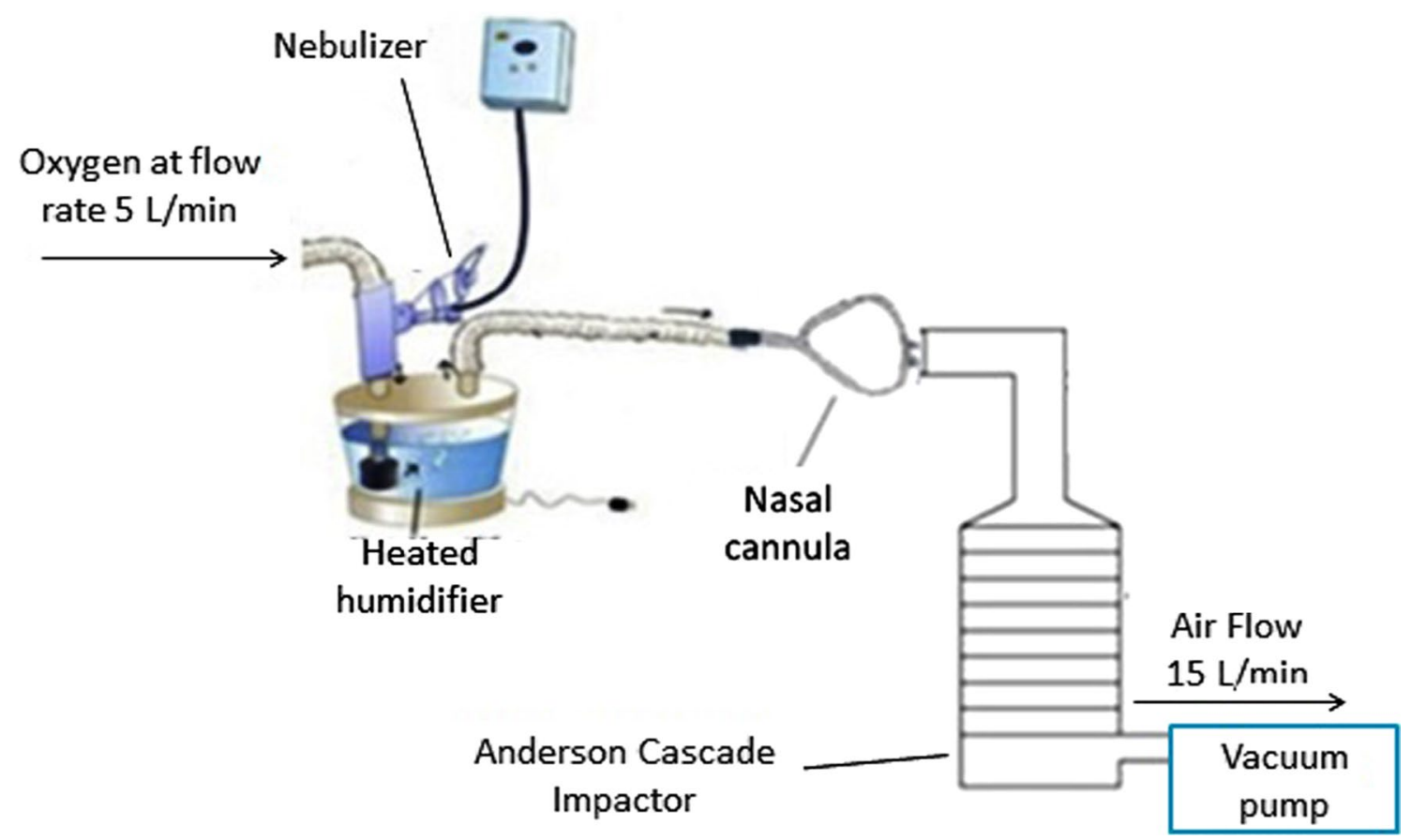

Fig. 4 Schematic diagram showing the measurement of the particle size distribution, by Anderson Cascade Impactor, using high flow nasal cannula system at oxygen flow $5 \mathrm{~L} \mathrm{~min}{ }^{-1}$. Modified from Madney et al. [19] SOLO vibrating mesh nebulizer was connected to the HFNC system upstream just before the humidifier which was connected to the nasal cannula. Cooled Anderson Cascade Impactor (inhalation flow rate of

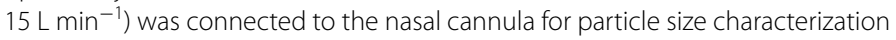

using acetonitrile in a water mixture $(90: 10 \mathrm{v} / \mathrm{v})$. For the inhalation filter, it was first sonicated with the acetonitrile-water mixture. Amounts of salbutamol were quantified using high-performance liquid chromatography (HPLC). Salbutamol was quantified with high-performance liquid chromatography linked to an ultraviolet detector. Samples of the acetonitrile washings $(100 \mu \mathrm{L})$ were eluted on a $25 \mathrm{~mm}$ by $4.6 \mathrm{~mm}$ ZORBAX Eclipse Plus C18, ODS1 column (Agilent, Santa Clara, California) using a 90:10 (v/v) acetonitrile and water mobile phase that also contained $0.1 \%$ phosphoric acid pumped at a flow of $1 \mathrm{~mL} \mathrm{~min}^{-1}$ (1260 Infinity preparative pump, G1361A, Agilent). The detector (1260 Infinity Diode array detector VL, G131SD, Agilent) was set at $225 \mathrm{~nm}$ and calibration was done using solutions ranging from 4 to $100 \mu \mathrm{g} \mathrm{mL}^{-1}$ (weight/volume). The limit of detection used was $0.3 \mu \mathrm{g} \mathrm{mL}^{-1}$, and the lower limit of quantification was $2.5 \mu \mathrm{g} \mathrm{mL}^{-1}$ [26].

\subsection{Measurement of the particle size distribution}

The three above-mentioned techniques were tested for detecting aerosol particle size distribution, that would reach the patient, using a cooled Anderson Cascade Impactor $[\mathrm{ACI}]$ (Copley Scientific Ltd, Nottingham,
$\mathrm{UK})$ at an inhalation flow rate of $15 \mathrm{~L} \mathrm{~min}^{-1}$ [27]. This vacuum flow, $15 \mathrm{~L} \mathrm{~min}^{-1}$, was provided by a vacuum pump (Brook Crompton, Huddersfield, UK). The flow rate was measured using an electronic digital flow meter (MKS Instruments, Andover, USA). First, the ACI with its plates in-situ was placed in a refrigerator at $5{ }^{\circ} \mathrm{C}$ for $60 \mathrm{~min}$ before starting the study [27]. As shown in Fig. 4, the setup was the same as in determining the TID in the HFNC system except that ACI was connected to the nasal cannula instead of the filter holder and the breathing simulator. In the case of the two BiPAP pressures (high and low), ACI was also inserted instead of the filter holder and the breathing simulator as shown in Fig. 5. In each technique of the three, the aerosol particle size distribution was determined 3 times $(n=3)$. SOLO nebulization was continued to dryness. The amount of salbutamol entrained on ACI stages and filter stage were collected using an acetonitrile-water mixture (90:10 v/v) and the final filter in the ACI was sonicated first with the same mixture used for TID determination. The amounts were quantified using the same HPLC method mentioned in TID determination [26].

The fine particle dose (FPD), fine particle fraction (FPF), and the mass median aerodynamic diameter (MMAD) was determined using Copley Inhaler Testing 
Data Analysis Software (CITDAS, Copley Scientific, Nottingham, UK) impactor data analysis software.

\subsection{Statistical analysis}

All data are expressed as mean $\pm \mathrm{SD}$. One-way analysis of variance (ANOVA) with the application of least significant difference (LSD) correction was used to compare the three different techniques with SPSSV17.0 (SPSS Inc., Chicago, USA). Statistical significance was taken at a $95 \%$ confidence interval $(p \leq 0.05)$.

\section{Results}

As shown in Table 1, the TID delivered using BiPAP mode at low inspiratory pressure was the highest followed by HFNC then BiPAP at high inspiratory pressure. However, the delivered dose using the HFNC system was non-significantly different from neither low nor high inspiratory pressure BiPAP modes. There was a significant difference only between low and high inspiratory pressure BiPAP modes $(p=0.014)$.

The amount of salbutamol that was lost in the tubes was also greatest in the case of low-inspiratory pressure BiPAP mode followed by HFNC then high inspiratory pressure BiPAP, as shown in Table 1 with a significant difference between high inspiratory pressure BiPAP mode and both HFNC $(p=0.046)$ and low inspiratory pressure BiPAP mode $(p=0.039)$. No significant difference was found in the amount left in the SOLO nebulization chamber using the three techniques.

As shown in Table 2, the low inspiratory pressure BiPAP mode delivered the highest FPD followed by
Table 1 Mean \pm SD of the amount of salbutamol deposited on inhalation filter [total inhalable dose (TID)], the losses in tubes and left in SOLO reservoir in $\mu \mathrm{g}(\mathrm{n}=5)$

\begin{tabular}{lcll}
\hline Amount & Tubes & Solo & Inhalation f \\
\hline Low BiPAP & $1341.85 \pm 644.97$ & $238.98 \pm 100.86$ & $2301.52 \pm 337.27$ \\
High BiPAP & $799.44 \pm 42.84$ & $273.20 \pm 20.28$ & $1192.62 \pm 283.8$ \\
Nasal cannula & $1292.72 \pm 163.74$ & $257.23 \pm 66.05$ & $1478.90 \pm 172.08$ \\
\hline
\end{tabular}

Table 2 Mean $\pm S D$ of Fine Particle Dose (FPD), in $\mu \mathrm{g}$, Fine Particle Fraction (FPF), in \%, and mass median aerodynamic diameter (MMAD), in $\mu \mathrm{g}$, of delivered dose of salbutamol $(n=3)$

\begin{tabular}{lcll}
\hline Amount/percent & FPD $(\boldsymbol{\mu g})$ & FPF $(\%)$ & MMAD $(\boldsymbol{\mu g})$ \\
\hline Low BiPAP & $1268.47 \pm 263.21$ & $63.11 \pm 10.02$ & $2.3 \pm 0.72$ \\
High BiPAP & $337.51 \pm 39.98$ & $30.025 \pm 1.38$ & $4.9 \pm 0.9$ \\
Nasal cannula & $856.71 \pm 24.78$ & $78.14 \pm 1.34$ & $0.47 \pm 0.21$ \\
\hline
\end{tabular}

HFNC system than high inspiratory pressure BiPAP with a significant difference between the three modes $(p<0.05)$. However, the highest FPF was delivered by the HFNC system followed by low then high inspiratory pressure BiPAP as shown in Table 2 with a significant difference between all the three modes $(p<0.05)$. The HFNC system had the smallest MMAD followed by low then high inspiratory pressure BiPAP as shown in Table 2. The MMAD of the HFNC was significantly smaller than the high inspiratory pressure BiPAP (at $p=0.002$ ). There was

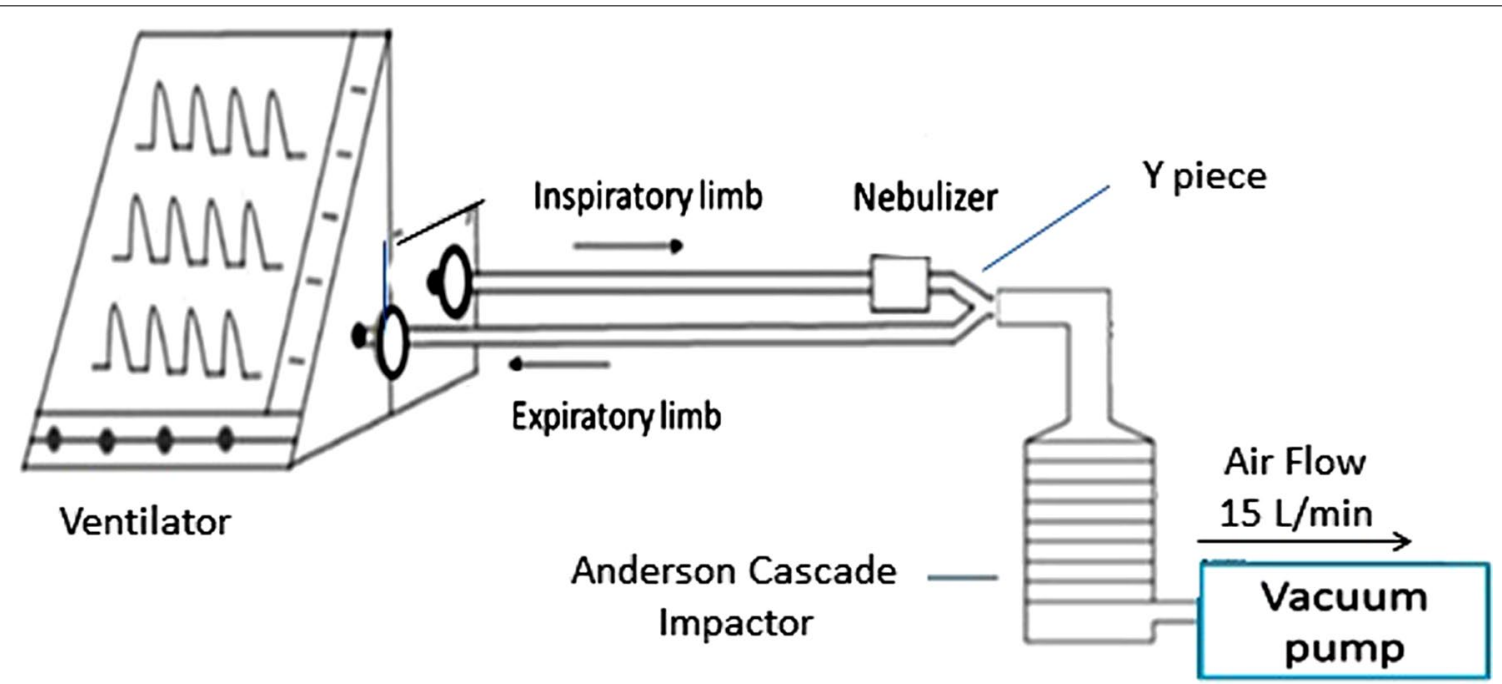

Fig. 5 Schematic diagram showing the measurement of the particle size distribution, by Anderson Cascade Impactor, using BiPAP mode. Modified from ElHansy et al. [24]. SOLO vibrating mesh nebulizer was inserted in the ventilation circuit in the inspiratory limb of the BiPAP (before the Y piece of the dual limb ventilation circuit). Cooled Anderson Cascade Impactor (inhalation flow rate of $15 \mathrm{~L} \mathrm{~min}{ }^{-1}$ ) was connected to the $Y$ piece. The bi-level ventilator was adjusted at two different pressures; IPAP/EPAP 20/5 cm water and IPAP/EPAP $10 / 5 \mathrm{~cm}$ water 
also a significant difference in the MMAD between high inspiratory pressure BiPAP mode and low inspiratory pressure BiPAP mode (at $p=0.027$ ).

\section{Discussion}

In the present study, SOLO was inserted in the inspiratory limb before Y-piece in the BiPAP ventilation model as it was previously found to deliver the highest amount of drug compared to that when integrated into the mask [28, 29]. However, when using the HFNC system, we inserted SOLO before the humidification chamber (immediately upstream) as it was shown to increase the inhalable mass, FPF, decreased nebulization duration and no nebulizer driving gas can interfere with the inspired oxygen fraction $[13,23]$. Besides, the HFNC system was operated in the present study at a low flow rate of $5 \mathrm{~L} \mathrm{~min}^{-1}$, as it was found that increasing the high flow therapy flow rate significantly decreased the respirable mass [13,23]. Placing the nebulizer after the humidifier (downstream) before the nasal cannula was found to significantly decrease the aerosolized drug delivery. This is explained by that when placing the nebulizer just before the nasal cannula, the flows which come through the heated tube suddenly find resistance change due to the smaller diameter of the nasal cannula which causes gas flow turbulence so more drug accumulates within the adaptor and the drug delivery to the cannula and the patient decreases [25]. Bhashyam et al. reported that vibrating mesh nebulizer produces aerosol within the range of $5 \mathrm{~mm}$ although that leaves nasal prongs was is around $2 \mathrm{~mm}$ [12]. That causes loss of aerosol within the circuit. The latter can cause the annoying liquid to come from the nasal prongs ito the nose of the patients if lying down. Consequently, inserting a nebulizer before the humidifier may cause the loss of the large particles within the humidifier itself preventing this annoying liquid $[23,30,31]$. That caused the HFNC system to have the least MMAD followed by low inspiratory pressure BiPAP then high inspiratory pressure BiPAP.

The current study showed that increasing IPAP from 10 to $20 \mathrm{~cm}$ water significantly decreased the delivered TID, and FPD. This is in accordance with the results of Velasco and Berliniski who showed that the drug delivery decreased when IPAP increased from 15 to $20 \mathrm{~cm}$ water, at the same EPAP [28]. On the other hand, Chatmongkolchart et al. in-vitro study revealed that when using a single limb circuit, the delivery efficiency improved when there was an increase in IPAP and the nebulizer was inserted after the exhalation port proximal to the lung model [32]. This may be attributed to the single limb setting used in this previous study compared to the dual limbs used in the current study. The single-limb ventilator causes aerosol to return retrograde to the ventilator circuit limb on exhalation increasing the aerosol delivery in the next inspiration, especially with higher IPAP and lower EPAP, by increasing the tidal volume and inspiratory time [32].

The HFNC system delivered a slightly lower, but nonsignificantly, TID of the salbutamol than BiPAP at low inspiratory pressure. However, TID by HFNC was higher than BiPAP at high inspiratory pressure, with no significant different. The TID delivered by the HFNC system was higher than the amounts reported by Bhashyam et al. at comparatively low flow rates of 3 and $5 \mathrm{~L} \mathrm{~min}^{-1}$ [12]. Also, it was higher than those detected by Perry et al. [25]. This may be attributed to that they connected the nebulizer proximal to the nasal cannula after the end of the heated tube and downstream from the Fisher \& Paykel heater/humidifier or Vapotherm 2000 humidifier and also, the difference in HFNC systems.

Depending on TID results, the amount of salbutamol delivered by $5 \mathrm{mg}$ through high inspiratory pressure BiPAP circuit is equal to that would be delivered by $4.032 \mathrm{mg}$ through HFNC circuit and $2.59 \mathrm{mg}$ through low inspiratory pressure BiPAP circuit. Depending on the FPD results, the amount of salbutamol delivered by $5 \mathrm{mg}$ through high inspiratory BiPAP circuit is equal to that would be delivered by $1.969 \mathrm{mg}$ through HFNC circuit, and $1.33 \mathrm{mg}$ through low inspiratory BiPAP circuit. So, increasing inspiratory positive airway pressure causes a reduction in the delivered dose to the patient. Also, great care should be taken in adjusting the dose when a patient is changed from a mode to another.

\section{Conclusion}

The HFNC system at low oxygen flow resulted in the least MMAD, and the highest FPF. Low inspiratory pressure BiPAP delivered the highest TID and FPD. Increasing the inspiratory positive airway pressure in BiPAP, from 10 to $20 \mathrm{~cm}$ water, decreased the TID and FPF nearly by half. Using a high-flow nasal cannula delivered a TID that was non-significant from that delivered by low inspiratory pressure BiPAP. The results of the current study suggest that there must be dose adjustment upon changing between the used techniques. Further in-vivo studies are recommended using the same settings used in this current study.

\section{Abbreviations}

HFNC: High flow nasal cannula; BiPAP: Biphasic positive airway pressure; IPAP: Inspiratory positive airway pressure; TID: Total inhalable dose; ACl: Anderson Cascade Impactor; NIV: Non-invasive ventilation; CMV: Controlled mandatory ventilation; SIMV: Synchronized intermittent mandatory ventilation; AC: Assist control; IMV: Intermittent mandatory ventilation; CPAP: Continuous positive airway pressure; HFOV: High-frequency oscillatory ventilation; SOLO: Aerogen Solo vibrating mesh nebulizer; IPAP/EPAP: High pressure, inspiratory positive airway pressure/expiratory positive airway pressure; HPLC: High-performance liquid chromatography; FPD: Fine particle dose; FPF: Fine particle fraction; MMAD: Mass median aerodynamic diameter. 


\section{Acknowledgements \\ Not applicable.}

\section{Authors' contributions}

(1) Conception and design: MA, and NL. (2) Administrative support: All authors. (3) Provision of study materials: All authors. (4) Collection and assembly of data: ME. (5) Data analysis and interpretation: ME. (6) Manuscript writing: ME. (7) Final approval of manuscript: All authors. All authors read and approved the final manuscript.

\section{Funding}

There was no external funding for this study itself. All authors had full access to all of the data in this study and take complete responsibility for the integrity of the data and accuracy of the data analysis.

\section{Availability of data and materials}

The datasets analyzed during the current study are available from the corresponding author on reasonable request.

\section{Declarations}

\section{Ethics approval and consent to participate}

Not applicable.

\section{Consent for publication}

Not applicable.

\section{Competing interests}

The authors declare that they have no competing interests.

\section{Author details}

${ }^{1}$ Clinical Pharmacy Department, Faculty of Pharmacy, Beni-Suef University, Beni-Suef, Egypt. ${ }^{2}$ Department of Chest Diseases, Faculty of Medicine, BeniSuef University, Beni-Suef, Egypt. ${ }^{3}$ Clinical Pharmacology Department, Faculty of Medicine, Beni-Suef University, Beni-Suef, Egypt.

Received: 6 May 2021 Accepted: 3 November 2021

Published online: 20 November 2021

\section{References}

1. Tol G, Palmer J (2010) Principles of mechanical ventilation. Anaesth Intensive Care Med 11(4):125-128

2. Nava S, Hill N (2009) Non-invasive ventilation in acute respiratory failure. Lancet 374(9685):250-259

3. Ambrosino N, Foglio K, Rubini F et al (1995) Non-invasive mechanical ventilation in acute respiratory failure due to chronic obstructive pulmonary disease: correlates for success. Thorax 50(7):755-757

4. Dhand R (2008) Aerosol delivery during mechanical ventilation: from basic techniques to new devices. J Aerosol Med Pulm Drug Deliv 21(1):45-60

5. Saeed H, Rabea H, Abdelwahab NS et al (2020) Effects of nebulizer fill volume on the efficacy and safety of the bronchodilator. J Drug Deliv Sci Technol 56:101508

6. Seif SM, Elnady MA, Rabea H et al (2020) Effect of different connection adapters on aerosol delivery in invasive ventilation setting; an in-vitro study. J Drug Deliv Sci Technol 61:102177

7. Ugurlu AO, Sidhom SS, Khodabandeh A et al (2014) Use and outcomes of noninvasive positive pressure ventilation in acute care hospitals in Massachusetts. Chest 145(5):964-971

8. Dhand R (2012) Aerosol therapy in patients receiving noninvasive positive pressure ventilation. J Aerosol Med Pulm Drug Deliv 25(2):63-78

9. Crimi C, Noto A, Princi P et al (2010) A European survey of noninvasive ventilation practices. Eur Respir J 36(2):362-369

10. Ambrosino N, Vagheggini G (2008) Noninvasive positive pressure ventilation in the acute care setting: where are we? Eur Respir J 31(4):874-886

11. Stéphan F, Barrucand B, Petit P et al (2015) High-flow nasal oxygen vs noninvasive positive airway pressure in hypoxemic patients after cardiothoracic surgery: a randomized clinical trial. JAMA 313(23):2331-2339

12. Bhashyam AR, Wolf MT, Marcinkowski AL et al (2008) Aerosol delivery through nasal cannulas: an in vitro study. J Aerosol Med Pulm Drug Deliv 21(2):181-188

13. Réminiac F, Vecellio L, Heuzé-Vourc'h N et al (2016) Aerosol therapy in adults receiving high flow nasal cannula oxygen therapy. J Aerosol Med Pulm Drug Deliv 29(2):134-141

14. Ward JJ (2013) High-flow oxygen administration by nasal cannula for adult and perinatal patients. Respir Care 58(1):98-122

15. Sztrymf B, Messika J, Mayot T et al (2012) Impact of high-flow nasal cannula oxygen therapy on intensive care unit patients with acute respiratory failure: a prospective observational study. J Crit Care 27(3):324. e9-324.e13

16. Cuquemelle E, Pham T, Papon J-F et al (2012) Heated and humidified high-flow oxygen therapy reduces discomfort during hypoxemic respiratory failure. Respir Care 57(10):1571-1577

17. Frat J-P, Thille AW, Mercat A et al (2015) High-flow oxygen through nasal cannula in acute hypoxemic respiratory failure. N Engl J Med 372(23):2185-2196

18. Corley A, Caruana LR, Barnett AG et al (2011) Oxygen delivery through high-flow nasal cannulae increase end-expiratory lung volume and reduce respiratory rate in post-cardiac surgical patients. Br J Anaesth 107(6):998-1004

19. Madney YM, Laz NI, Elberry AA et al (2020) The influence of changing interfaces on aerosol delivery within high flow oxygen setting in adults: an in-vitro study. J Drug Deliv Sci Technol 55:101365

20. Papazian L, Corley A, Hess D et al (2016) Use of high-flow nasal cannula oxygenation in ICU adults: a narrative review. Intensive Care Med 42(9):1336-1349

21. Yu Y, Qian X, Liu C et al (2017) Effect of high-flow nasal cannula versus conventional oxygen therapy for patients with thoracoscopic lobectomy after extubation. Can Respir J 2017:7894631

22. Longest PW, Walenga RL, Son Y-J et al (2013) High-efficiency generation and delivery of aerosols through nasal cannula during noninvasive ventilation. J Aerosol Med Pulm Drug Deliv 26(5):266-279

23. Ari A, Harwood R, Sheard M et al (2011) In vitro comparison of heliox and oxygen in aerosol delivery using pediatric high flow nasal cannula. Pediatr Pulmonol 46(8):795-801

24. ElHansy MH, Boules ME, Farid $\mathrm{H}$ et al (2017) In vitro aerodynamic characteristics of aerosol delivered from different inhalation methods in mechanical ventilation. Pharm Dev Technol 22(6):844-849

25. Perry SA, Kesser KC, Geller DE et al (2013) Influences of cannula size and flow rate on aerosol drug delivery through the Vapotherm humidified high-flow nasal cannula system. Pediatr Crit Care Med 14(5):e250-e256

26. Abdelrahman MM (2018) Solid-phase extraction and HPLC-DAD for determination of salbutamol in urine samples. Anal Chem Lett 8(1):35-45

27. Abdelrahim ME (2011) Aerodynamic characteristics of nebulized terbutaline sulphate using the Andersen Cascade Impactor compared to the Next Generation Impactor. Pharm Dev Technol 16(2):137-145

28. Velasco J, Berlinski A (2018) Albuterol delivery efficiency in a pediatric model of noninvasive ventilation with double-limb circuit. Respir Care 63(2):141-146

29. Harb HS, Saeed H, Madney YM, et al. Update efficacy of aerosol therapy with noninvasive ventilator approach (non-invasive ventilation and nasal high flow). J Drug Deliv Sci Technol. 2020;101922.

30. Madney YM, Fathy M, Elberry AA et al (2017) Nebulizers and spacers for aerosol delivery through adult nasal cannula at low oxygen flow rate: an in-vitro study. J Drug Deliv Sci Technol 39:260-265

31. Réminiac F, Vecellio L, Loughlin RM et al (2017) Nasal high flow nebulization in infants and toddlers: an in vitro and in vivo scintigraphic study. Pediatr Pulmonol 52(3):337-344

32. Chatmongkolchart S, Schettino GP, Dillman C et al (2002) In vitro evaluation of aerosol bronchodilator delivery during noninvasive positive pressure ventilation: effect of ventilator settings and nebulizer position. Crit Care Med 30(11):2515-2519

\section{Publisher's Note}

Springer Nature remains neutral with regard to jurisdictional claims in published maps and institutional affiliations. 